\title{
Projecting armed conflict risk in Africa towards 2050 along the Shared Socio-economic Pathways: a machine learning approach
}

Jannis M. Hoch ${ }^{1 *}$, Sophie P. de Bruin ${ }^{1,2}$, Halvard Buhaug ${ }^{3,4}$, Nina von Uexkull ${ }^{5,3}$, Rens van Beek ${ }^{1}$, Niko Wanders ${ }^{1}$

1 Department of Physical Geography, Utrecht University, Utrecht, the Netherlands

2 PBL Netherlands Environmental Assessment Agency, the Hague, the Netherlands

3 Peace Research Institute Oslo (PRIO), Oslo, Norway

4 Department of Sociology and Political Science, Norwegian University of Science and Technology, Trondheim, Norway

5 Department of Economic History and International Relations, Stockholm University, Stockholm, Sweden

* corresponding author: j.m.hoch@uu.nl

Twitter: Jannis M. Hoch (@_jannis_h), Niko Wanders (@niko_wanders)

\section{Abstract}

In the past decade, several efforts have been made to project armed conflict risk into the future. One arising technique is the use of machine-learning (ML) models. In this study we explore its opportunities to project sub-national armed conflict risk for three shared socio-economic pathway (SSP) scenarios and three Representative Concentration Pathways (RCPs) by 2040-2050 in Africa, using the novel and open-source ML framework CoPro. Results are consistent with the underlying socioeconomic storylines of the SSPs, and the resulting out-of-sample armed conflict projections obtained with RandomForest classifiers agree with comparable studies. In SSP1-RCP2.6, conflict risk is low or absent in most regions, although the Horn of Africa and parts of Kenya, Tanzania and Mozambique continue to be conflict-prone. Conflict risk intensifies in the more severe SSP3-RCP6.0 scenario, especially in central Africa and large parts of western Africa. We specifically assessed the role of hydroclimatic indicators as drivers of armed conflict. Overall, their importance is limited but can differ locally depending on the overall sign of climate change impact and the contextual (socio-economic) factors defining the overall magnitude of those impacts. With our study being at the forefront of $\mathrm{ML}$ applications for conflict risk projections, we have identified various challenges for this arising scientific field. A major concern is the inconsistent data availability of observed conflict events as well as of socio-economic indicators for the various SSPs. Nevertheless, ML models such as the one presented here are a viable way forward in the field of armed conflict risk projections, and can help to inform the policy-making process with respect to climate security. 


\section{Introduction}

Without effective climate mitigation measures and continuing human-induced ecological degradation, environmental pressures on livelihoods are expected to worsen in several regions around the world (Adger et al., 2014). A more contested impact of environmental degradation, especially through climate change impacts, is the increased risk of violent conflict (Buhaug et al., 2014; Hsiang et al., 2013; Koubi, 2019; Mach et al., 2019). Political concern as well as scientific and security interests have hence been rising during the last decades. This has resulted in a maturing body of academic literature (von Uexkull and Buhaug, 2021), also feeding decision-making of intergovernmental institutions, such as the UN Security Council (Scott, 2015).

However, scientific consensus is still limited regarding the relevance and strength of mechanisms linking climate, environment, and armed conflict risk (Koubi, 2019). Recent conclusions differ due to, inter alia, the use of different data proxies, timescales and geographical scales, and definitions of conflict.

Nevertheless, several conditions - including low socio-economic development and socioeconomic shocks, the strength of governments, and the recent history of armed conflict - are generally accepted as contextual risk factors (Mach et al., 2019). It is under these conditions that climatic and environmental drivers may increase conflict risk (see Mach et al. (2019) for potential linkages). Already conflict-prone countries, which lack good governance systems and depend on climate-sensitive resources such as precipitation for rain-fed agriculture, are found to be most vulnerable to the adverse effects of hydro-climatic changes (Almer et al., 2017; Gleick, 2014; von Uexkull, 2014).

With intensifying climate change impacts and changing local water availability, gaining insights into the role of water-related climate change impacts in future armed conflict risk is needed. Recent attempts mostly aimed at developing early warning mechanisms forecasting conflict risk for a limited time horizon (Hegre et al., 2017). Examples are the Water, Peace and Security initiative (WPS Partnership, 2021) and the violence early-warning system ViEWS (Hegre et al., 2021, 2019). For those instruments, accuracy and forecasting skills are paramount. With their prediction horizon up to 36 months (ViEWS) they are suited to inform, for example, short-term policy making and interventions. They are not, however, intended to explore security implications of plausible, though possibly inaccurate, long-term scenarios aiding capacity building and long-term policy processes.

Incomplete knowledge about the relations between conflict drivers and the lack of sufficient observational data make it challenging to project long-term conflict risk (Cederman and Weidmann, 2017). Nevertheless, making projection ensembles without claiming to make absolute and accurate predictions is a legitimate way to improve estimates of the uncertainty bounds (Maier et al., 2016). The main aim of the projections is to assess plausible developments along alternative scenarios rather than predict the onset of an event. This approach is already successfully adopted in other scientific disciplines such as flood and drought risk projections (Hirabayashi et al., 2013; Wanders et al., 2015). The insights obtained from these long-term projections can then provide a starting point for hotspot identification, development of adaptive policy options, and the preparation for rare events (Mahmoud et al., 2009; van Beek et al., 2020).

Thus far, only few studies address the long-term future risk of conflict in general (de Bruin et al., 2021; von Uexkull and Buhaug, 2021). Examples are Hegre et al. (2013) using a multinomial logit model to predict conflict towards 2050; Witmer et al. (2017) projecting future regions at conflict risk under different climate and socio-economic scenarios until 2065 using various Representative Concentration Pathways (RCPs) and Shared Socio-economic Pathways (SSPs); and Hegre et al. (2016) projecting conflict towards 2100 under alternative SSPs. Up until today, Witmer et al. (2017) is the only conflict study engaging with the SSP-RCP framework (van Vuuren et al., 2014). 
Here, we use CoPro, a novel open-source machine-learning (ML) model (Hoch et al., 2021), to disentangle historical relations between conflict and socio-economic as well as hydro-climatic variables. ML models have already been identified as a viable way forward in conflict risk projection Colaresi and Mahmood (2017). Based on detected historical relations, we apply CoPro to project future regions at risk. With this first data-driven analysis of future conflict risk we aim to (i) contribute to the currently under-studied field of long-term conflict risk projections (de Bruin et al., 2021), (ii) evaluate model ability to quantify future changes of regions-at-risk using ML techniques (iii) evaluate the changes in conflict risk across scenarios, and (iv) (re)assess the importance of (insinuated) socioeconomic and hydro-climatic drivers of armed conflict.

Climate change will impact future societies via multiple ways, for example a greater spatiotemporal variability of water availability. To which extent we need to prepare for a more violent tomorrow, and what key (hydro-climatic) drivers need to be tackled to mitigate this development, is thus the central question of this paper. And whilst this is an exciting scientific challenge, there is also an important societal dimension to it. Only if we manage to align our current policy decisions with future needs, it will be possible to live in an equitable and peaceful way. Understanding how different future pathways will look like can facilitate shaping this process, and the use of data-driven approaches may be an important cornerstone in this.

\section{Data and methods}

\subsection{Spatio-temporal properties}

We applied CoPro over entire Africa (Hoch et al., 2021). The analysis was conducted at an annual temporal resolution which suffices for long-term outlooks of conflict risk. As spatial aggregation level, we employed water provinces (Straatsma et al. (2020); see Figure 1), a balanced sub-national representation of topographic, hydro-climatic, and administrative properties permitting useful generalisations. Provinces with less than $20,000 \mathrm{~km}^{2}$ area were merged with a neighbouring province to avoid under-catch of dynamics in those small areas, yielding in total 293 water provinces.

To train, test, and evaluate CoPro, we focussed on the period 1995 until 2015. This period was chosen as it is the longest intersect of available historic hydro-climatic, socio-economic, and conflict data. We then projected conflict forward in time until 2050. Projections follow three alternative scenarios of societal development, the SSPs (O'Neill et al., 2017). These SSPs are internally coherent and follow different narratives of socio-economic and environmental development. As not all SSPs are compatible with all representative concentration pathways (RCPs), the following SSP-RCP combinations were employed to reflect an as wide as possible range of socio-economic and climate developments: SSP1 with RCP 2.6, SSP2 with RCP 4.5, and SSP3 with RCP 6.0. Details are given in Appendix A.

To assess the relative importance of hydro-climatic drivers, we performed an attribution experiment: one simulation including both hydro-climatic and socio-economic data ("SSP-RCP run" hereafter), and another one with socio-economic data only ("SSP run" hereafter). 


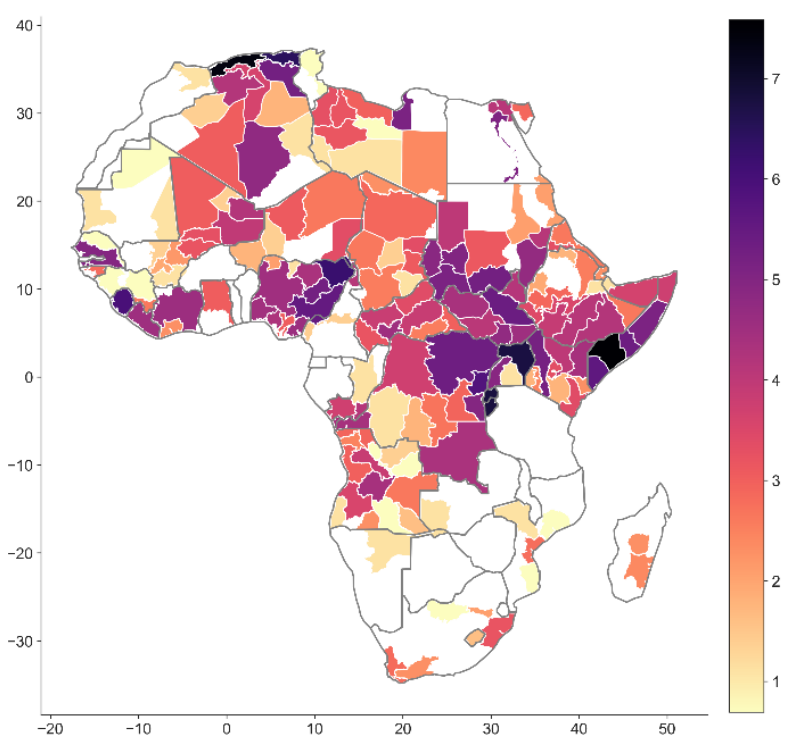

Figure 1: Geometric boundaries of the water provinces in Africa plus log-scaled number of observed conflict events in the reference period (1995-2015) per water province scaled with polygon size.

\subsection{Data description}

For our analysis, we use indicators (see Table 1) already quantified in the SSP projections that can theoretically and empirically be established as drivers of conflict risk. An important guiding factor for data selection was the availability of consistent historical and projected data. For this study we used a selection of currently available variables, however as more data becomes available in the future, follow-up attempts can aim at expanding the data used. A more elaborated overview of data properties can be found in Appendix B.

The following socio-economic indicators are used: governance ${ }^{1}$ (Andrijevic et al., 2020), logtransformed population count (van Huijstee et al., 2018), log-transformed gross domestic product per capita based on purchasing power parity (GDP per cap (PPP); Murakami and Yamagata (2019)), and education expressed as the mean number of schooling years at age 15-19 (Wittgenstein Centre for Demography and Global Human Capital, 2018). To ensure that historical and projection data align, we bias-corrected all socio-economic variables from the SSP projections to ensure that no shifts occur moving from the historical record to the projections. We used the last available observation and compared this to the first year from the projection to establish the bias in the projections. We assumed that this additive bias remained constant throughout the projections and corrected all future years accordingly.

As hydro-climatic indicators we selected the yearly anomalies of precipitation, evaporation, flood volume, and upper soil storage. The indicators were selected to represent overall climate variability (precipitation and evaporation) and on-the-ground hydrological effects (floods and soil storage as proxy for droughts (Basche et al., 2016; Silva, 2017)). All environmental variables were simulated with the global hydrological model PCR-GLOBWB (Sutanudjaja et al., 2018). For climate projections under the various RCPs, the model was forced with CMIP5 output from the global climate model (GCM) IPSL, derived from the bias-corrected ISI-MIP ensemble (Warszawski et al., 2014) to ensure consistency between the historical and future records.

${ }^{1}$ Although governance is typically not subsumed under socio-economic indicators, we do so here for the sake of easier readability and traceability throughout the manuscript 
For all variables the mean value per water province was determined except for population count for which the sum was determined. A one-year time lag was applied for all indicators to account for reverse causality between drivers and effect.

To account for history of conflict, a well-established driver of conflict occurrence (Hegre and Sambanis, 2006; Mach et al., 2019), we sampled whether armed conflict took place in the previous year. Additionally, we sampled whether a conflict event occurred in any of the neighbouring provinces in the previous year to account for 'spill-over effects' (Bara, 2014; Goldstone et al., 2010). A binary value was assigned depending on the outcome.

For conflict event observations, we employed the UCDP Georeferenced Event Dataset (GED) v20.1 (Pettersson and Öberg, 2020; Sundberg and Melander, 2013). From the available types of conflict we selected events on 'state-based armed conflict' and 'non-state conflict', indicating deadly conflict between the government and one or more non-state actors or two non-state actors respectively. Per year, a binary value was assigned per water province if at least one conflict event was reported in this specific year in this location or not.

Table 1: Overview of indicators used to project conflict risk (see Appendix B for more details)

\begin{tabular}{|l|l|l|}
\hline SSP indicators & RCP indicators & Conflict-related indicators \\
\hline Governance & Precipitation & Conflict in previous year \\
\hline Population count & Evaporation & $\begin{array}{l}\text { Conflict in neighbouring } \\
\text { province in previous year }\end{array}$ \\
\hline $\begin{array}{l}\text { Gross domestic productivity } \\
\text { (GDP) (Purchasing power } \\
\text { parity (PPP)) per capita }\end{array}$ & Flood volume & \\
\hline Education & Upper soil storage & \\
\hline
\end{tabular}

\subsection{Set-up of the machine learning model}

By means of using ML methods, we try to determine the historic relation between the indicators ("sample data") and conflict risk ("target data"). We assumed that this relation is stationary in time and applied it to make projections of future conflict risk. This approach thus assumes that the established link does not change between historical training period and future projections, a potential limitation already identified in previous research (Bowlsby et al., 2020). Although it is impossible to derive a dynamic relation, we believe that using $M L$ has the distinct advantage that it can deal with non-linearity between sample and target data. Additionally, this relation is directly derived from data instead of being pre-defined.

\subsubsection{The reference period 1995-2015}

To derive a stable relation, we employed the open-source software package CoPro v0.0.8 (Hoch et al., 2021, 2021) to train a Random Forest (RF) classifier model with 20 years of data (19952015). See Hoch et al. (2021) for the model description and the documentation for an elaborated explanation ${ }^{2}$. Figure 2 depicts a flow chart of the modelling workflow.

For each year of the reference period 1995-2015, values were extracted for all indicators. The resulting sample data and target data was appended annually, yielding a 'master matrix'. To minimize the risk of overfitting our model, $100 \mathrm{RF}$ trees are initialised. For each tree, $70 \%$ of the data points in the master matrix was randomly selected to train the model and the remaining $30 \%$ to make

${ }^{2}$ A model overview can be found in Hoch et al. (2021), a full model documentation is provided at https://copro.readthedocs.io/en/v0.0.8 
and evaluate predictions of conflict occurrence. CoPro therefore follows a different modelling approach than comparable studies, for example Hegre et al. $(2013,2016)$ and Witmer et al. (2017), which use a conventional regression model framework.

These projections were subsequently evaluated against observed conflict events and a range of evaluation metrics was computed (see section 3.1). Additionally, the relative importance of each indicator was assessed to improve our understanding of their relation with conflict occurrence.

While these metrics focus on the accuracy of all data points, it is also important to assess accuracy per water province. Hence, the fraction of correct predictions (FOP) per polygon $i$ is determined as follows:

$$
F O P_{i}=\frac{\sum c p_{i}}{N_{i}}
$$

where $c p$ denotes a correct projection and $N$ the number of projections made for a given polygon $i$. FOP can thus range between 0 (no correct projection) and 1 (only correct projections). Computing the FOP allows for identifying provinces where model output is more likely to be correct.

\subsubsection{Projections of conflict risk by 2050}

From the end of the reference period until 2050, we make annual out-of-sample forward projections. To maintain internal consistency of each projection pathway, this was done for each viable SSP-RCP combination and each of the $100 \mathrm{RF}$ trees separately.

The last reference year (2015) is used to initialize the conflict risk projections, since all projections are based on indicator and conflict values of the previous year due to the one-year time lag. All projections after 2016 draw upon the projected binary maps of conflict occurrence in the previous time step of each individual RF tree, while the remaining indicator values are provided by input data.

At the end of each projection year, the outcomes of all trees are combined per water province. We therefore do not only obtain a final projection for the year 2050, but also all years in between, yielding the possibility to track conflict risk development over time (Appendix C).

As a quantitative evaluation of the long-term projections is not possible, model output is evaluated qualitatively and compared across all scenarios for the SSP-RCP and SSP run separately. Therefore, the probability of conflict $(P O C)$ per polygon $i$ was annually determined over all $100 \mathrm{RF}$ trees $(T)$ as:

$$
P O C_{i}=\frac{\sum_{t}^{T} P(c)_{i, t}}{T}
$$

where $P(c)$ denotes the projected probability of conflict per polygon $i$ and RT tree $t$. 


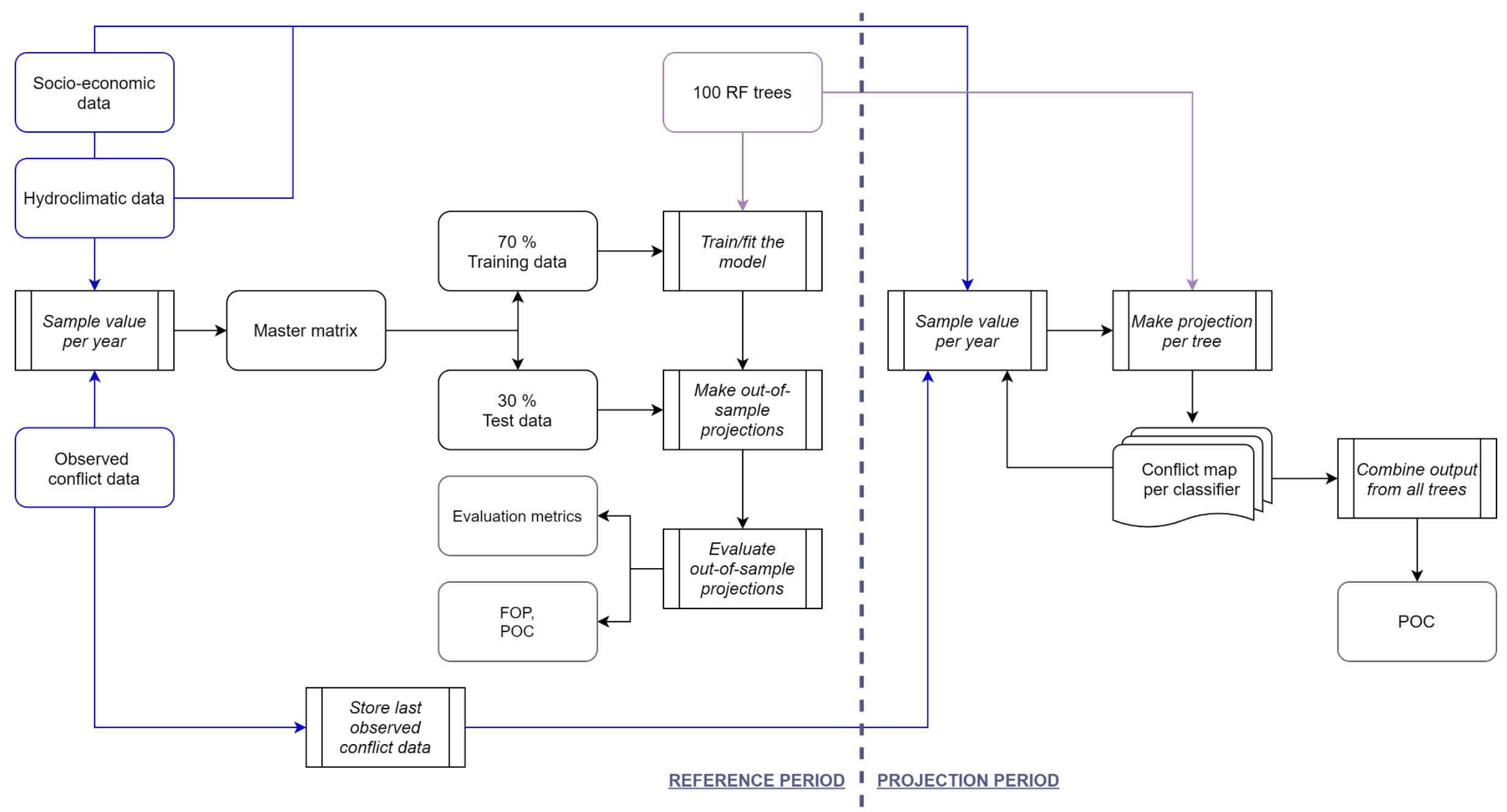

Figure 2: Flowchart of the machine learning approach followed by CoPro for this study 


\section{Results and discussion}

\subsection{Model validation}

The reference situation 1995-2015 is used to evaluate the performance of the SSP-RCP run and the SSP run. In general, only marginal differences in predictive performance are reported between the SSP-RCP run and the RCP run (Table 2). Including or excluding hydro-climatic information has thus only limited effect on our ability to correctly predict conflict risk in the current study design.

Table 2: Overview of computed model evaluation scores for both SSP-RCP run and SSP run for the period 1995-2015

\begin{tabular}{|l|c|c|}
\hline & SSP-RCP run & SSP run \\
\hline Average ROC-AUC score & 0.903 & 0.909 \\
\hline Average precision-score & 0.750 & 0.775 \\
\hline Average accuracy & 0.873 & 0.871 \\
\hline Average precision & & 0.737 \\
\hline Average recall & 0.763 & 0.640 \\
\hline Average Brier-score & 0.623 & 0.094 \\
\hline
\end{tabular}
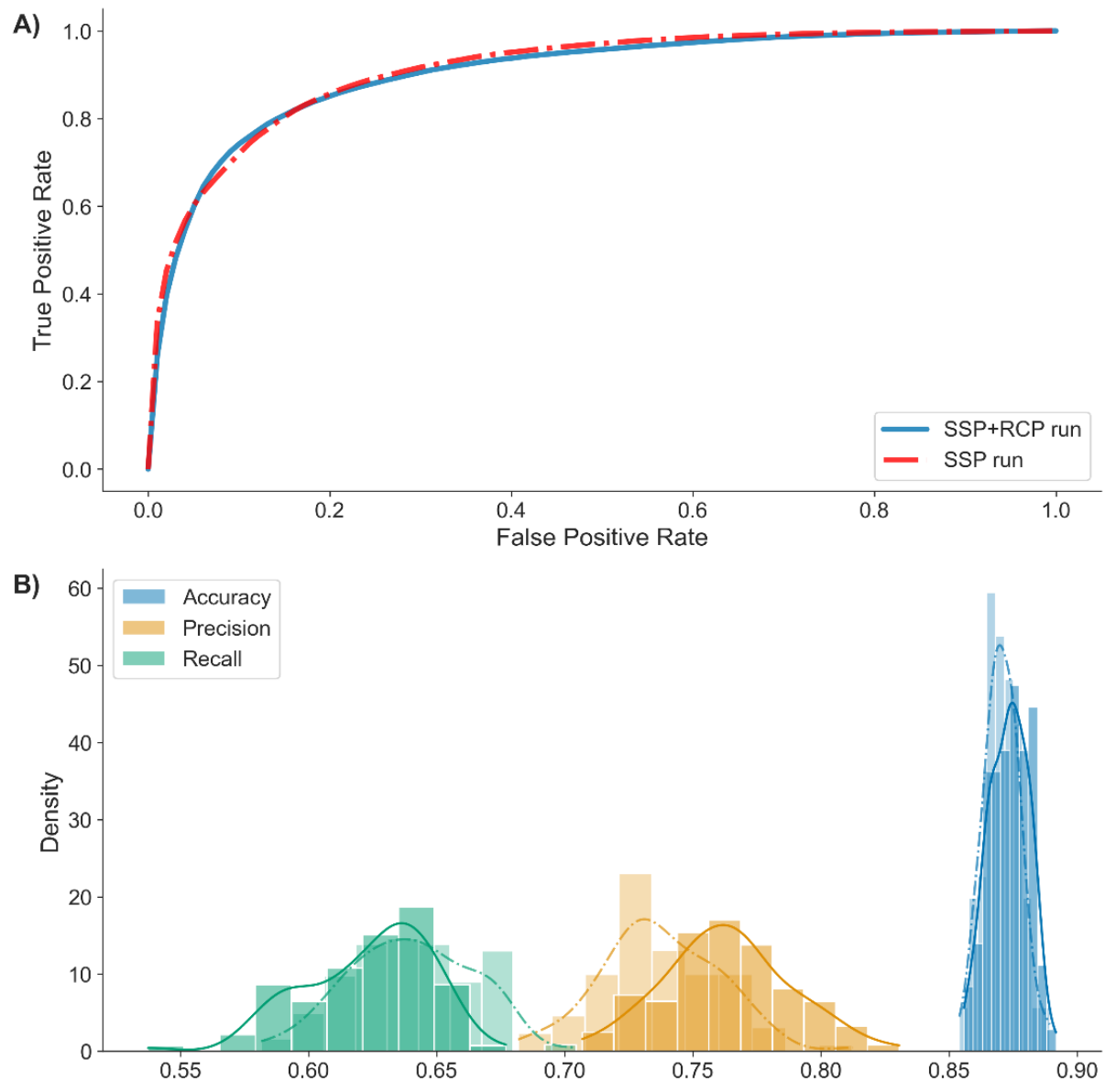

Figure 3: (A): ROC-curve averaged over 100 model repetitions for both SSP-RCP run and SSP run. (B): probability density functions for accuracy, precision, recall for SSP-RCP and SSP runs. Distribution for SSP run is shown with dotted line and shaded bars.

${ }^{3}$ Note that precision and precision-score are different. While the former computes actual precision of model output, the latter is based on the precision-recall curve. 
For both runs, the overall model performance is good as indicated by ROC-AUC scores above 0.9 (see also Figure $3 \mathrm{~A}$ ) with the SSP run showing a slightly better performance. The computed ROCAUC score is in line with previous studies projecting conflict (Colaresi and Mahmood, 2017; Hegre et al., 2013). The mean Brier-score, measuring the mean squared difference between the predicted probability and the actual outcome, is slightly higher than computed by Witmer et al. (2017) but comparable with Hegre et al. (2019).

Overall accuracy, that is the fraction of correct classifications, is good in both runs. Mean precision (the ability of the classifier not to label a sample as "conflict" that is "non-conflict") is slightly higher in the SSP-RCP run whereas recall, which expresses the ability of the classifier to find all positive samples, is lower than in the SSP run. The relatively low recall in both runs is most likely rooted in the imbalanced training dataset due to the small fraction of conflicts in there ( $22 \%)$.

The spatial model performance strongly depends on the number of conflict events between 1995 and 2015 per water province (see Figure 4A). Predictions of conflict are more accurate in very conflict-rich provinces, while provinces with no or little conflict observations are correctly identified as such by the model; polygons with an 'intermediate' number of reported conflict events tend to be less accurately predicted.

A)

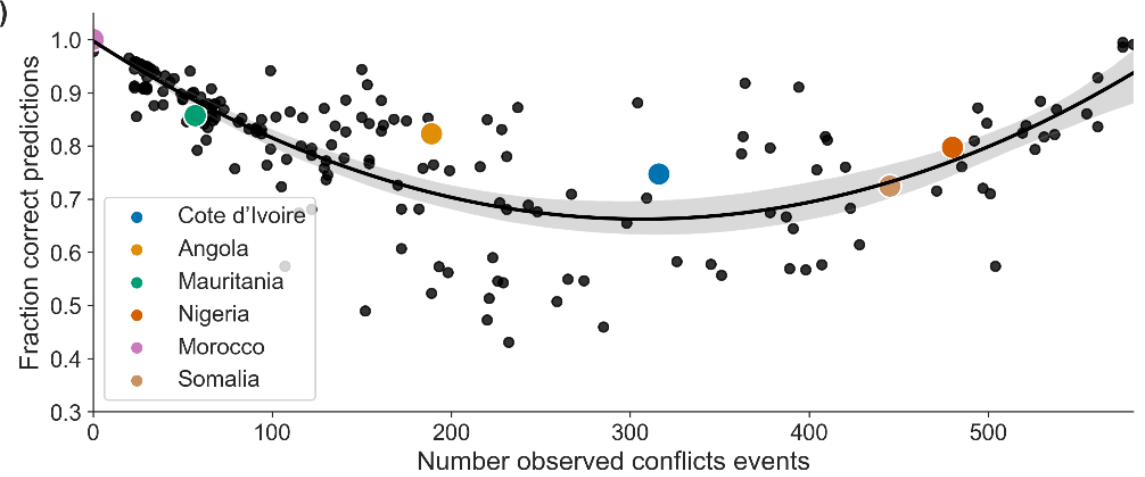

B)

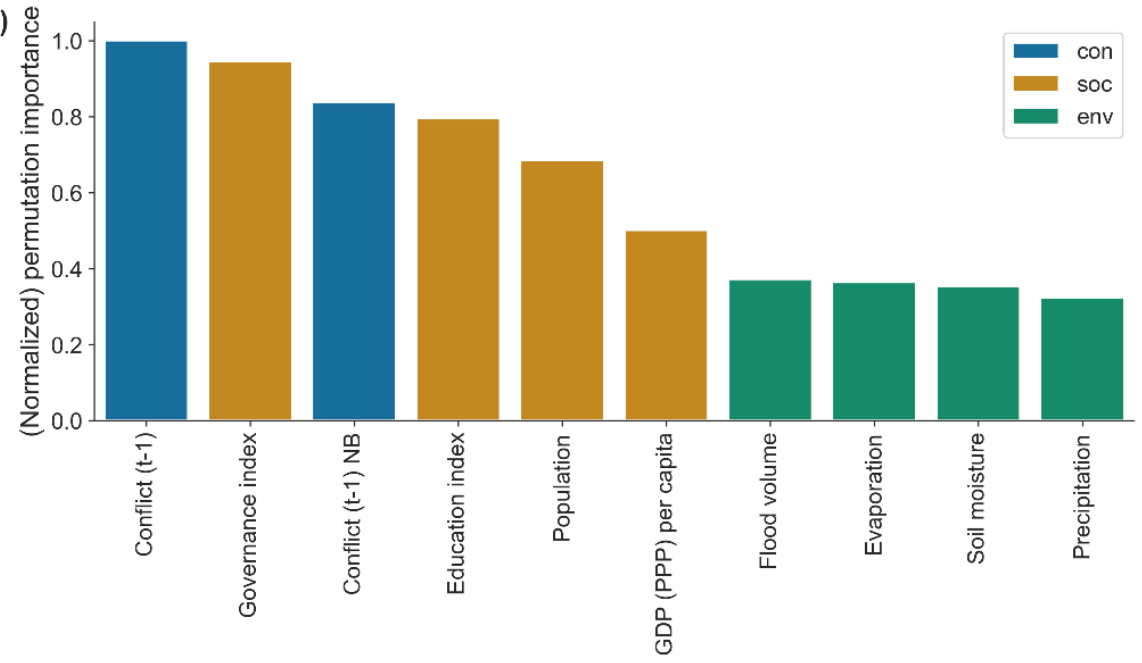

Figure 4: A) scatter plot of FOP and the number of reported conflict events per polygon, also highlighted for selected water provinces and all SSPS. Six water provinces have been picked to serve as an example. Selected water provinces are: Mauritania, Hodh ech Chargui; Somalia, Mudug; Nigeria, Ondo; Morocco, Sous-Massa-Draa; Cote d'Ivoire-Savanes; Angola, Cuanza Sul; B) permutation importance for projections made with reference period data for SSP-RCP run.

Areas with low model accuracy in the reference situation as expressed by low fraction of correct predictions (FOC) values are southern Algeria as well as parts of the Sahel and Sahara, Congo, Somalia, and Ethiopia (Figure 5A). There is, however, not a single country for which all water provinces are inaccurately modelled - an advantage of using a sub-national aggregation level. Conflict-prone provinces as identified with high POC in the out-of-sample validations are, inter alia, the Horn of Africa, 
South Sudan, Nigeria, and the north-eastern part of Congo (Figure 5B). These projections agree with observations of current conflict areas as reported in the conflict database (see Figure 1).
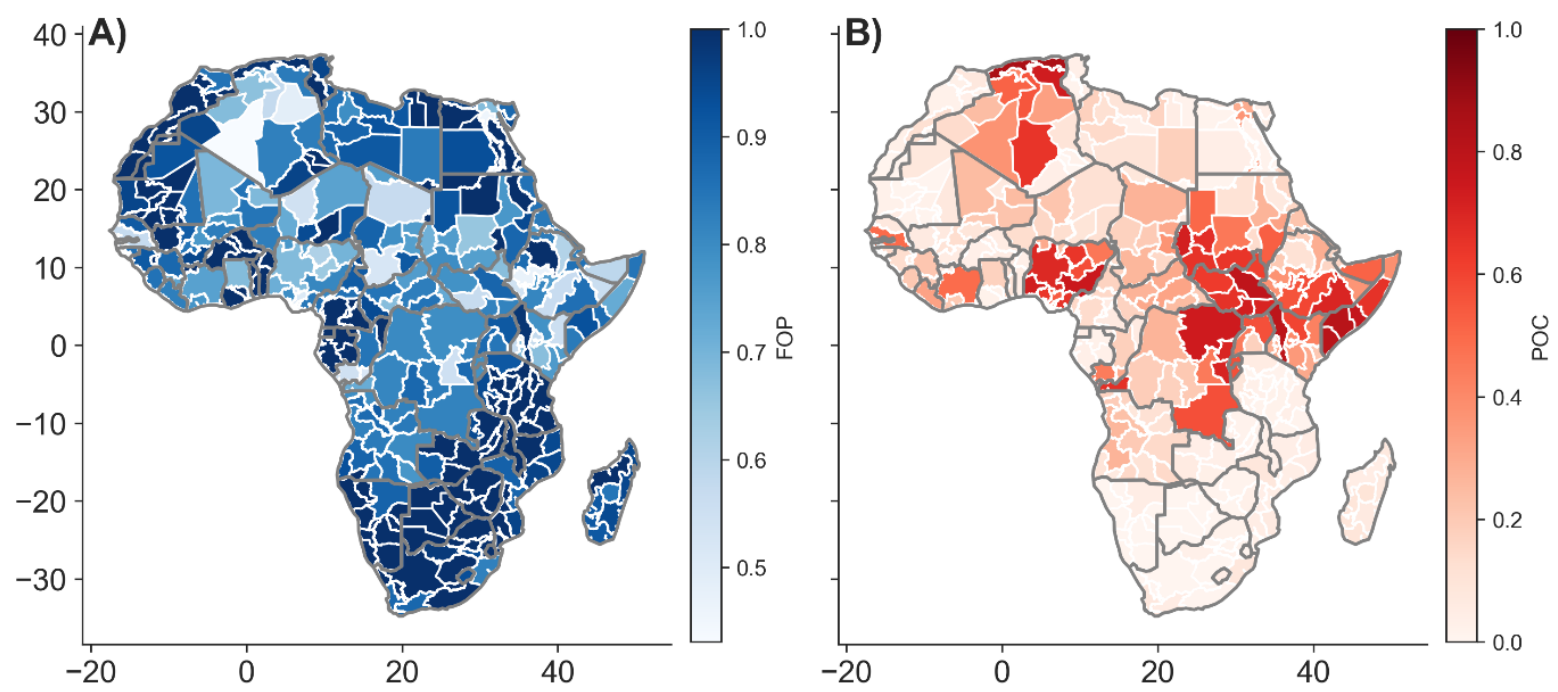

Figure 5: Fraction of correct prediction made per water province (A) as well as predicted probability of conflict (B) for the reference period 1995-2015 obtained with the SSP-RCP run.

\subsection{Major drivers of conflict}

To assess indicator importance in RF models, there are multiple approaches (Tyralis et al., 2019). Here, we computed the permutation importance per indicator, that is the decrease in model score when the original relation between indicator and dependent values is broken (Breiman, 2001). Permutation importance was subsequently normalized relative to the indicator with the highest value to improve comparability. It is important to note that permutation importance does not provide information about the direction of variable influence on conflict. Aggregating importance is therefore not sensible as different variables can have countervailing effects.

The indicator with the highest importance is conflict in the previous year. History of conflict is well-described in literature and established as an important driver of conflict (Bara, 2014; Goldstone et al., 2010; Hegre and Sambanis, 2006; Mach et al., 2019). Previous conflict in neighbouring water provinces plays also plays an important role and is ranked third (Bara, 2014; Goldstone et al., 2010).

The second ranked indicator is governance (Figure 4B) which is found to be an important risk factor for conflict in earlier studies (Besley and Persson, 2011; Goldstone et al., 2010; Mach et al., 2019).

Education and population count are ranked four and five. Education may have indirect impacts via socio-economic divisions as well as varying degrees of political inclusion (Barakat and Urdal, 2009; Brown, 2011). A high population count is found to multiply the risk on conflict as a result of the higher chance of confrontations (Raleigh and Hegre, 2009).

GDP per capita (PPP) is found to be of less importance than other socio-economic indicators. This may be surprising since low economic development is often mentioned as a major risk factor for conflict (Fearon and Laitin, 2003; Mach et al., 2019) although it is partly a product of accounting for human development (education) which often is ignored in conflict studies.

Overall, the hydro-climatic indicators are found to be of least importance. This agrees with prevalent findings underlining that climate-related factors are only impactful under certain socioeconomic conditions (Mach et al., 2019). Here, anomalies of flood volume and evaporation are of slightly more importance than anomalies of soil moisture and precipitation, yet the overall differences are marginal. The small difference between the hydro-climatic indicators indicates an overall limited 
relevance regardless which indicator is considered. A plausible explanation of the limited relevance of these indicators could be that hydrological extremes only occur in a specific part of the year, while annual averages are used here.

The overall picture therefore shows that CoPro can capture the main historical spatial and temporal variability of conflict occurrence over Africa. Issues remain with provinces where conflict events are sparse. With respect to indicator importance, model results follow the current understanding of contemporaneous literature by assigning higher importance to history of conflict and socio-economic drivers than to hydro-climatic variables.

\subsection{Scenario projections}

\subsubsection{Output analysis}

Comparing projected conflict risk in 2050, we found that only a limited number of water provinces was reported as conflict-prone. This is likely due to the rather 'erratic' nature of conflict whose (repeated) onset and end can be anytime and is highly complex (see also Appendix C). Just evaluating projections for one year may therefore yield rather arbitrary results as it is merely based on a snapshot. We therefore decided to average output over the period 2040-2050 to obtain a more robust picture.

Projections made reflect the scenario storylines and show an intensification of conflict probability in SSP3-RCP6.0 compared to SSP1-RCP2.6 (Figure 6), although spread is lower in all scenarios than in the reference situation. This can partly be attributed to the rather bright economic growth projections in all scenarios for low-income countries (Buhaug and Vestby, 2019). We also find that not only the spatial distribution but also the POC varies for the SSP-RCP runs compared to the reference situation (see Figure 5B). Given the more sustainable development of SSP1-RCP2.6 compared to today, a reduction of conflict-prone areas can be expected at least for this scenario (Hegre et al., 2016).

Figure 6 furthermore shows a spread and intensification of POC over Africa for the SSP-RCP runs. While for SSP1-RCP2.6 the highest POC is obtained for North and West Africa as well as for (parts of) Mozambique, Tanzania, and Kenya, SSP3-RCP6.0 exhibits high POC for additional regions. For SSP3RCP6.0, and to a lesser extent for SSP2-RCP4.5, almost the entire Sahara and Sahel zone face armed conflict risk. In the Horn of Africa, POC is projected to increase in SSP3-RCP6.0. Other areas projected to experience increased POC in SSP3-RCP6.0 are large parts of Angola, the Congo, and coastal West Africa. Conflicts in Morocco are projected to spread into Mauritania and intensify. These areas overlap only partly with those having a high POC for the reference situation (see Figure 5B).

Several differences can be observed between SSP-RCP and SSP runs. For the SSP1 scenario, overall differences are small. In SSP2, especially Northern and parts of Central Africa are projected to be more conflict-prone considering the SSP data only, whereas parts of the Sahel and southern Africa are projected to have a decreased POC. In SSP3, differences are found to increase especially in the Sahel, showing both a higher POC (northern Sahel) and a lower POC (southern Sahel) when considering SSP data only. In general, results depict that the influence, both negative and positive, of climate change becomes more pronounced with higher RCPs.

To attribute this in more detail, a closer look at RCP 6.0 reveals that in northern Africa projected decreases in foremost precipitation and evaporation (Figure 7) correspond with higher POCs in the SSP-RCP run compared to the SSP run. In the Congo, increases in flood volume may add to an increased POC in the SSP-RCP scenario. Meanwhile, increased levels of precipitation in Western Africa and limited parts of the Sahel and Eastern Africa could explain a lower POC in the SSP-RCP scenario. For other regions, the hydro-climatic patterns are too ambiguous to make a substantive influence on the projections. 

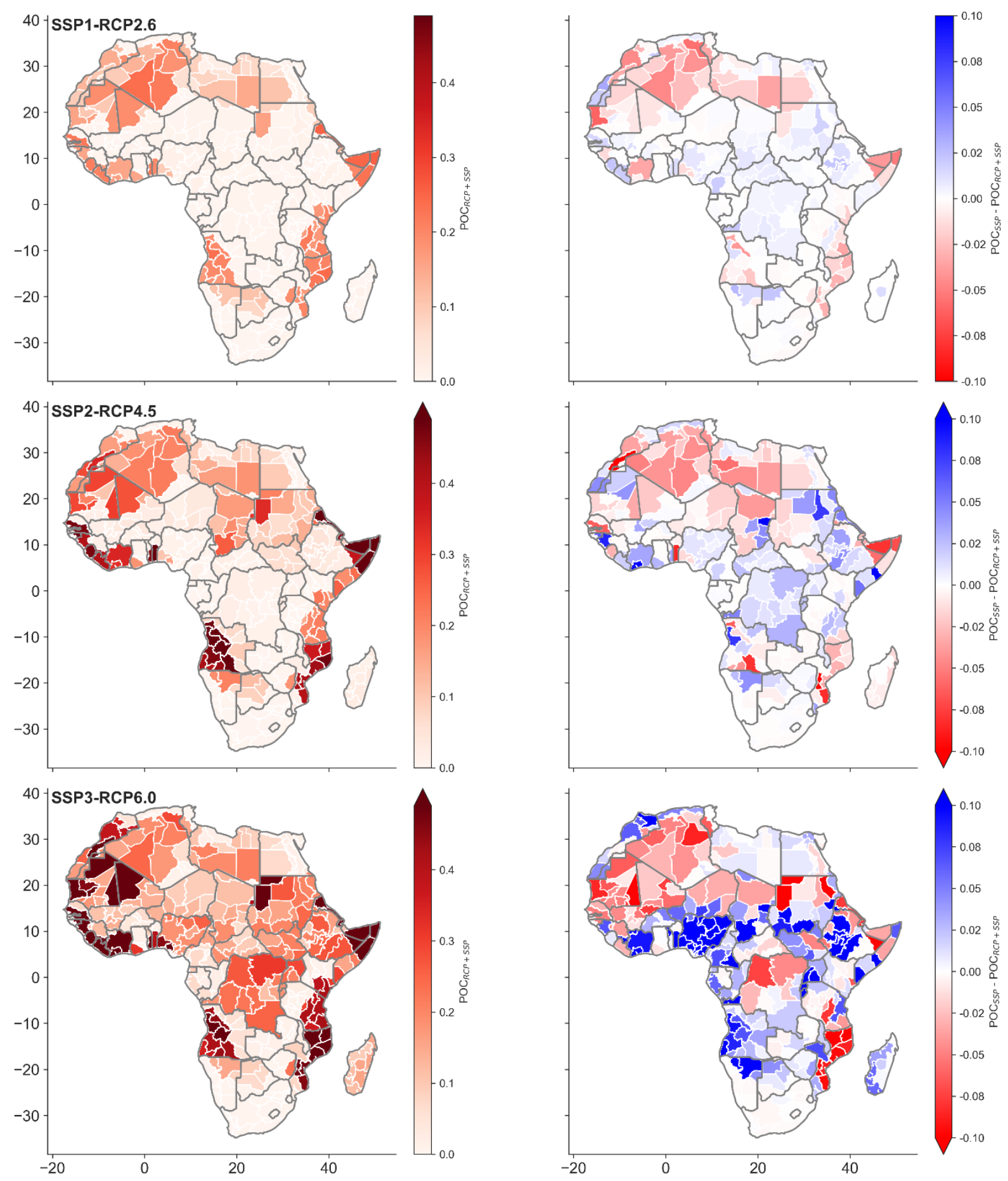

Figure 6 (left) projected probability of conflict (POC) per water province averaged over period 2040-2050 for the SSP-RCP run; (right) difference between simulated POC for SSP run and SSP-RCP run per water province. 

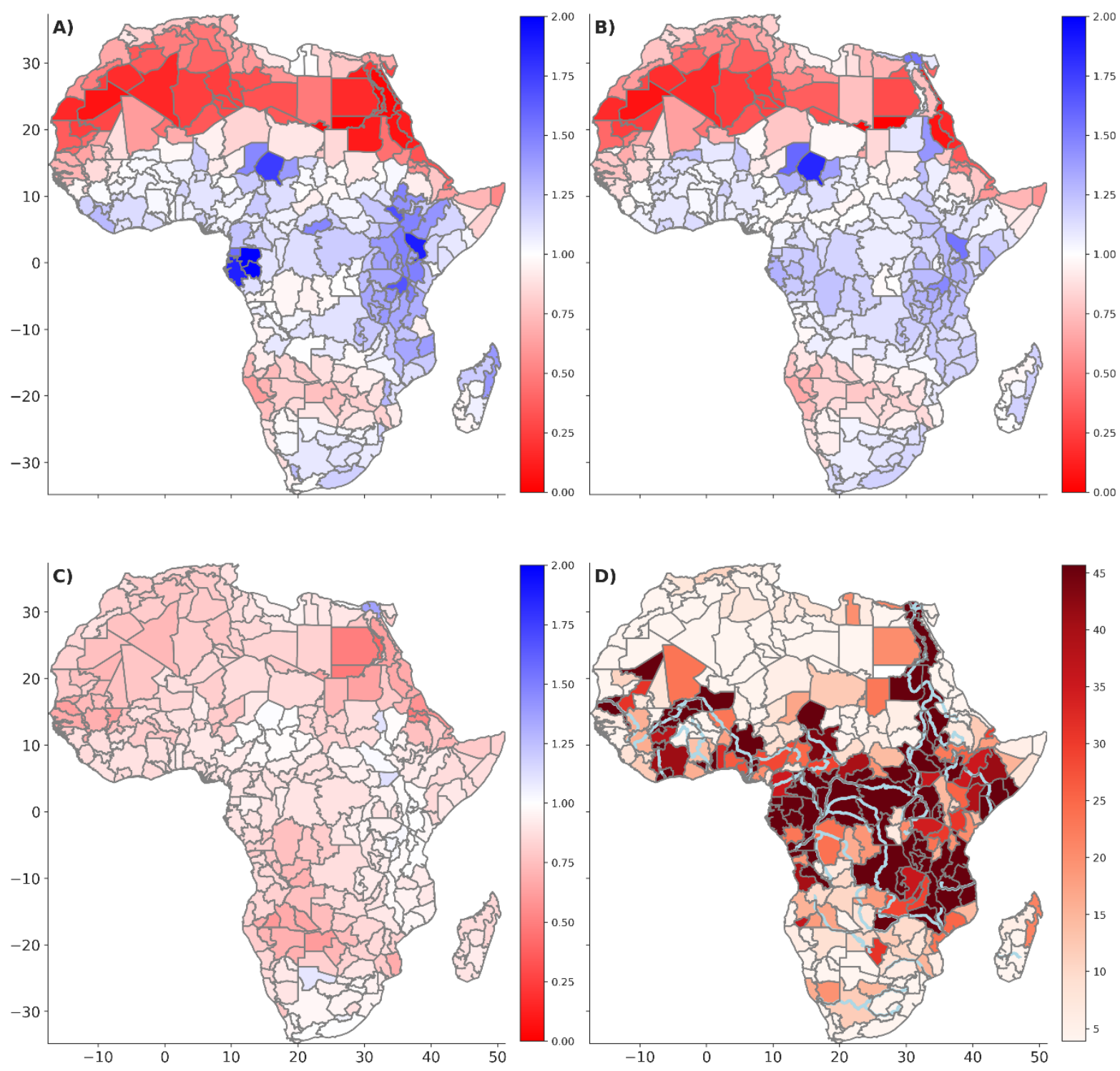

Figure 7: Absolute increase or decrease of each hydro-climatic indicator used in the model between period 20402050 compared to $1995-2015$ under RCP 6.0 per water province. Mean values per period were compared. A: Precipitation. B: Evaporation. C: Soil Moisture content. D: Flood volume.

\subsubsection{Output benchmark}

Benchmarking our results with those obtained by Witmer et al. (2017) who provide projections for SSP2 for 2041-2050 for sub-Saharan Africa, yields a similar picture given the range of differences in used data, model, methodology and so forth.

Witmer et al. (2017) also project relatively higher armed conflict risk along the West coast of Africa, in Angola, Mozambique, and the Horn of Africa. In contrast to our results, they predict more conflict in the inland of Africa, for example Congo, the South of Sudan and Chad, North Nigeria and Zimbabwe. For those inland areas, hydro-climatic indicators may alleviate conflict probability in our model which can explain parts of the discrepancies between model outputs. To be able to make a more robust statement, a thorough benchmarking study would be needed.

\subsubsection{Projection uncertainties}

A clear caveat in making these projections is the use of historical relations. Relations will most likely not remain stable over time; especially when climate change impacts worsen, its role is likely to increase with respect to the reference situation (Mach et al., 2019). Also Bowlsby et al. (2020) point 
out that the drivers of instability are not constant over time and that care must be taken when interpreting projection studies based on historical relations. This limitation could be overcome by using more advanced deep-learning and self-learning ML models. However, these more complex models make it also more difficult to understand the input-output relations between drivers and conflict risk.

Furthermore, the impact of hydro-climatic data must be assessed carefully as climate change is quantified differently in different GCMs. The here applied IPSL model therefore provides only one out of multiple possible realizations of future climate. IPSL was selected as it projects changes that are in the mean of the full ensemble of CMIP5 GCM models. However, the sign of change and magnitude of change may be different using alternative GCM output.

Still, results exhibit coherent consistency across the outputs for various SSP-RCP combinations as the temporal development of POC agrees with the underlying scenario storylines (Appendix C). In the end, we cannot claim with certainty how interactions and relations will develop in the future, and how armed conflict risk will be distributed in space and time. As projections in general can at best work as realizations of imaginable futures (de Bruin et al., 2021), it would not be credible to pretend that we hold this knowledge, nor that it can be accurately included into models. As such, the here shown conflict maps are possible, after all evaluations credible, realizations of many possible realizations, indicating that there may be marked spatial deviations in conflict risk depending on the followed scenario.

\section{Conclusions and recommendations}

To project future areas at risk of armed conflict, we employed the open-source machinelearning model CoPro to produce maps of regions-at-risk for various scenarios in Africa for the period 2040-2050. Also, we compared the relative impact of hydro-climatic variables on conflict occurrence. This study is on the forefront of using machine-learning models for conflict risk projections (Colaresi and Mahmood, 2017). By using data-driven approaches, existing model designs can be complemented and theoretical insights can be contributed to the on-going debate on the potential impacts of climate change on armed conflict.

Results indicate a more peaceful future compared to current conditions for the sustainable scenario SSP1-RCP2.6. We moreover find that under SSP2-RCP4.5 and SSP3-RCP6.0 conflict risk will increase, particularly in the Horn of Africa, parts of western Africa and parts of Angola, Mozambique, Tanzania and Kenya. These results are coherent with the underlying scenario storylines and other studies. Besides, our results show that for some areas, changes in hydro-climatic indicators have a distinct impact of conflict risk: while for Northern Africa and larger parts of Eastern Africa including the Horn of Africa this impact is negative, areas in the West and northern part of the Sahel it may be positive. Since the runs performed are more experiments than depictions of the real world with its complexity, these findings must be, however, interpreted carefully.

A wider range of quantified SSP indicators, as available for RCPs, would allow for ensemble projections and thus for mapping their uncertainties. Until then, we are limited to available sources including too bright projections of economic growth for low-income countries (Buhaug and Vestby, 2019). Currently, ensemble projection are only possible for RCP indicators derived from various GCMs. In follow-up studies, the ensemble output from GCMs should be used to confirm (or dismiss) our findings about the impact of hydro-climatic indicators.

On top of that, we recommend investigating the role of on-the-ground impact of the meteorological drivers precipitation and temperature. Changes thereof cannot be translated directly to changes in conflict, but it is rather the local impact that is decisive. Example candidates are the impact of climate change on groundwater levels (Döring, 2020), actual flood and drought risk (Ide et al., 2021; von Uexkull, 2014), and crop production (von Uexkull et al., 2016). 
This study merely focused on climate change impact of hydrology-related indicators. Other climate-related factors that might inform conflict risk, such as heat waves, are therefore not (yet) considered. Besides, the use of annual averages does not capture changes in, for example, timing and intensity of the rainy season, and cumulative effects building up over time. Future work should hence also try to include these effects. With the flexible structure of CoPro and the implemented machinelearning approach, the provided maps of conflict risk can be updated as new insights evolve and novel data sources become available.

We found that data availability is a major constraint for advancing data-driven projections of armed conflict risk. Since the distribution of observed conflict events versus "no-conflict events" is imbalanced towards the latter, the model will most likely predict conflict only for instances where the main driving factors coincide. As shown in Figure 4A, transitional areas are more difficult to predict. Indeed, both Eck (2012) and Ide and Scheffran (2014) show that the commonly used conflict data-sets for statistical inferences cover only a fraction of actual conflict events. Additional observational data would hence already improve the model skill. Furthermore, only drivers that have been projected within the SSP framework could be employed, whereas the literature offers additional contextual variables of importance, such as political discrimination and grievances between groups (Cederman et al., 2013). When improved quantitative data in accordance with the various SSPs becomes available, data-driven conflict risk projections can be advanced.

Adverse climate change impacts intensifying in many regions in the next decades raise concerns for peace and security. As precise knowledge about 'where' and 'when' of conflict onset is impossible to obtain for long-term projections, following various scenarios and producing consistent maps of possible conflict risk realizations may facilitate informing the policy-making process. Based on these conflict maps, the potential consequences of today's decision-making on long-term conflict development can become tangible. The present study points to the benefits for peace of investing in economic, human, and political development and maintaining sustainable demographic change in line with SSP1 over nationalism and protectionism in line with SSP3. In this setting, our study shows that projecting conflict risk with machine-learning approaches may be a viable way forward towards more insights into the delicate interplay of climate change and conflict.

\section{Data availability}

The open-access and open-source model code of CoPro used to perform the simulations can be found on Zenodo (Hoch et al., 2021).

\section{Acknowledgements}

$\mathrm{JH}$ and $\mathrm{SdB}$ acknowledge funding from an Utrecht University Pathways to Sustainability Acceleration Grant. HB acknowledges funding from the Research Council of Norway, grant 268135. NW acknowledges funding from NWO 016.Veni.181.049. NvU acknowledges funding from Mistra Geopolitics. We would like to acknowledge the participants of a workshop in March '20: Stijn van Weezel (Twente University), Ruben Dahm, Karin Meijer (Deltares), Stefan van Esch, Joost Knoop, Ben ten Brink (all PBL). Additional thanks go to Edwin Sutanudjaja (Utrecht University) and Joyce Bosmans (Radboud University Nijmegen) for providing PCR-GLOBWB output. 


\section{References}

Adger, W.N., Pulhin, J.M., Barnett, J., Dabelko, G.D., Hovelsrud, G.K., Levy, M., Spring, Ú.O., Vogel, C.H., Adams, H., Hodbod, J., Kent, S., Tarazona, M., Aldunce, P., Leichenko, R., 2014. Human security, in: Climate Change 2014: Impacts, Adaptation, and Vulnerability. Part A: Global and Sectoral Aspects. Contribution of Working Group II to the Fifth Assessment Report of the Intergovernmental Panel on Climate Change. Cambridge University Press, Cambridge, pp. 755-791.

Almer, C., Laurent-Lucchetti, J., Oechslin, M., 2017. Water scarcity and rioting: Disaggregated evidence from Sub-Saharan Africa. Journal of Environmental Economics and Management 86, 193-209. https://doi.org/10.1016/j.jeem.2017.06.002

Andrijevic, M., Crespo Cuaresma, J., Muttarak, R., Schleussner, C.-F., 2020. Governance in socioeconomic pathways and its role for future adaptive capacity. Nature Sustainability 3, 3541. https://doi.org/10.1038/s41893-019-0405-0

Bara, C., 2014. Incentives and opportunities: A complexity-oriented explanation of violent ethnic conflict. Journal of Peace Research 51, 696-710. https://doi.org/10.1177/0022343314534458

Barakat, B., Urdal, H., 2009. Breaking The Waves ? Does Education Mediate The Relationship Between Youth Bulges And Political Violence?, Policy Research Working Papers. The World Bank. https://doi.org/10.1596/1813-9450-5114

Basche, A.D., Kaspar, T.C., Archontoulis, S.V., Jaynes, D.B., Sauer, T.J., Parkin, T.B., Miguez, F.E., 2016. Soil water improvements with the long-term use of a winter rye cover crop. Agricultural Water Management 172, 40-50. https://doi.org/10.1016/j.agwat.2016.04.006

Besley, T., Persson, T., 2011. The Logic of Political Violence. The Quarterly Journal of Economics 126, 1411-1445. https://doi.org/10.1093/qje/qjr025

Bowlsby, D., Chenoweth, E., Hendrix, C., Moyer, J.D., 2020. The Future is a Moving Target: Predicting Political Instability. British Journal of Political Science 50, 1405-1417. https://doi.org/10.1017/S0007123418000443

Breiman, L., 2001. Random Forests. Machine Learning 45, 5-32. https://doi.org/10.1023/A:1010933404324

Brown, G.K., 2011. The influence of education on violent conflict and peace: Inequality, opportunity and the management of diversity. Prospects 41, 191-204. https://doi.org/10.1007/s11125011-9186-6

Buhaug, H., Nordkvelle, J., Bernauer, T., Böhmelt, T., Brzoska, M., Busby, J.W., Ciccone, A., Fjelde, H., Gartzke, E., Gleditsch, N.P., 2014. One effect to rule them all? A comment on climate and conflict. Climatic Change 127, 391-397. https://doi.org/10.1007/s10584-014-1266-1

Buhaug, H., Vestby, J., 2019. On Growth Projections in the Shared Socioeconomic Pathways. Global Environmental Politics 19, 118-132. https://doi.org/10.1162/glep_a_00525

Cederman, L.-E., Gleditsch, K.S., Buhaug, H., 2013. Inequality, Grievances, and Civil War. Cambridge University Press, Cambridge.

Cederman, L.-E., Weidmann, N.B., 2017. Predicting armed conflict: Time to adjust our expectations? Science 355, 474-476. https://doi.org/10.1126/science.aal4483

Colaresi, M., Mahmood, Z., 2017. Do the robot: Lessons from machine learning to improve conflict forecasting. Journal of Peace Research 54, 193-214. https://doi.org/10.1177/0022343316682065

de Bruin, S.P., Hoch, J.M., von Uexkull, N., Buhaug, H., Demmers, J., Visser, H., Wanders, N., 2021. Projecting long-term armed conflict risk: an underappreciated field of inquiry? https://doi.org/10.31223/X5HS5W

Döring, S., 2020. Come rain, or come wells: How access to groundwater affects communal violence. Political Geography 76, 102073. https://doi.org/10.1016/j.polgeo.2019.102073

Eck, K., 2012. In data we trust? A comparison of UCDP GED and ACLED conflict events datasets. Cooperation and Conflict 47, 124-141. https://doi.org/10.1177/0010836711434463 
Fearon, J.D., Laitin, D.D., 2003. Ethnicity, Insurgency, and Civil War. The American Political Science Review 97, 75-90.

Florczyk, A.J., Corbane, C., Ehrlich, D., Freire, S., Kemper, T., Maffenini, L., Melchiorri, M., Pesaresi, M., Politis, P., Schiavina, M., Sabo, F., Zanchetta, L., 2019. GHSL Data Package 2019 (No. EUR 29788 EN). Publications Office of the European Union, Luxembourg.

Gleick, P.H., 2014. Water, Drought, Climate Change, and Conflict in Syria. Weather, Climate, and Society 6, 331-340. https://doi.org/10.1175/WCAS-D-13-00059.1

Goldstone, J.A., Bates, R.H., Epstein, D.L., Gurr, T.R., Lustik, M.B., Marshall, M.G., Ulfelder, J., Woodward, M., 2010. A global model for forecasting political instability. American Journal of Political Science 54, 190-208. https://doi.org/10.1111/j.1540-5907.2009.00426.x

Hegre, H., Allansson, M., Basedau, M., Colaresi, M., Croicu, M., Fjelde, H., Hoyles, F., Hultman, L., Högbladh, S., Jansen, R., Mouhleb, N., Muhammad, S.A., Nilsson, D., Nygård, H.M., Olafsdottir, G., Petrova, K., Randahl, D., Rød, E.G., Schneider, G., 2019. ViEWS: A political violence earlywarning system. Journal of Peace Research 56, 155-174. https://doi.org/10.1177/0022343319823860

Hegre, H., Bell, C., Colaresi, M., Croicu, M., Hoyles, F., Jansen, R., Leis, M.R., Lindqvist-McGowan, A., Randahl, D., Rød, E.G., Vesco, P., 2021. ViEWS2020: Revising and evaluating the ViEWS political Violence Early-Warning System. Journal of Peace Research 58, 599-611. https://doi.org/10.1177/0022343320962157

Hegre, H., Buhaug, H., Calvin, K.V., Nordkvelle, J., Waldhoff, S.T., Gilmore, E., 2016. Forecasting civil conflict along the shared socioeconomic pathways. Environ. Res. Lett. 11, 054002. https://doi.org/10.1088/1748-9326/11/5/054002

Hegre, H., Karlsen, J., Nygård, H.M., Strand, H., Urdal, H., 2013. Predicting armed conflict, 2010-2050. International Studies Quarterly 57, 250-270. https://doi.org/doi.org/10.1111/isqu.12007

Hegre, H., Metternich, N.W., Nygård, H.M., Wucherpfennig, J., 2017. Introduction: Forecasting in peace research. Journal of Peace Research 54, 113-124. https://doi.org/10.1177/0022343317691330

Hegre, H., Sambanis, N., 2006. Sensitivity Analysis of Empirical Results on Civil War Onset. Journal of Conflict Resolution 50, 508-535. https://doi.org/10.1177/0022002706289303

Hirabayashi, Y., Mahendran, R., Koirala, S., Konoshima, L., Yamazaki, D., Watanabe, S., Kim, H., Kanae, S., 2013. Global flood risk under climate change. Nature Climate Change 3, 816-821. https://doi.org/10.1038/nclimate1911

Hoch, J.M., de Bruin, S., Wanders, N., 2021. CoPro: a data-driven modelling framework for conflict risk projections. Journal of Open Source Software 6, 2855. https://doi.org/10.21105/joss.02855

Hoch, J.M., de Bruin, S., Wanders, N., 2021. CoPro v0.0.8. Zenodo. https://doi.org/10.5281/zenodo.4968713

Hsiang, S.M., Burke, M., Miguel, E., 2013. Quantifying the influence of climate on human conflict. Science 341. https://doi.org/10.1126/science.1235367

Ide, T., Kristensen, A., Bartusevičius, H., 2021. First comes the river, then comes the conflict? A qualitative comparative analysis of flood-related political unrest. Journal of Peace Research 58, 83-97. https://doi.org/10.1177/0022343320966783

Ide, T., Scheffran, J., 2014. On climate, conflict and cumulation: suggestions for integrative cumulation of knowledge in the research on climate change and violent conflict. Global Change, Peace \& Security 26, 263-279. https://doi.org/10.1080/14781158.2014.924917

Koubi, V., 2019. Climate change and conflict. Annual Review of Political Science 22, 343-360. https://doi.org/10.1146/annurev-polisci-050317-070830

Mach, K.J., Adger, W.N., Buhaug, H., Burke, M., Fearon, J.D., Field, C.B., Hendrix, C.S., Kraan, C.M., Maystadt, J.-F., O'Loughlin, J., Roessler, P., Scheffran, J., Schultz, K.A., von Uexkull, N., 2020. Directions for Research on Climate and Conflict. Earth's Future 8, e2020EF001532. https://doi.org/10.1029/2020EF001532 
Mach, K.J., Kraan, C.M., Adger, W.N., Buhaug, H., Burke, M., Fearon, J.D., Field, C.B., Hendrix, C.S., Maystadt, J.-F., O'Loughlin, J., 2019. Climate as a risk factor for armed conflict. Nature 571, 193-197. https://doi.org/10.1038/s41586-019-1300-6

Mahmoud, M., Liu, Y., Hartmann, H., Stewart, S., Wagener, T., Semmens, D., Stewart, R., Gupta, H., Dominguez, D., Dominguez, F., 2009. A formal framework for scenario development in support of environmental decision-making. Environmental Modelling \& Software 24, 798-808.

Maier, H.R., Guillaume, J.H., van Delden, H., Riddell, G.A., Haasnoot, M., Kwakkel, J.H., 2016. An uncertain future, deep uncertainty, scenarios, robustness and adaptation: How do they fit together? Environmental Modelling \& Software 81, 154-164. https://doi.org/10.1016/j.envsoft.2016.03.014

Murakami, D., Yamagata, Y., 2019. Estimation of Gridded Population and GDP Scenarios with Spatially Explicit Statistical Downscaling. Sustainability 11, 2106. https://doi.org/10.3390/su11072106

O'Neill, B.C., Kriegler, E., Ebi, K.L., Kemp-Benedict, E., Riahi, K., Rothman, D.S., van Ruijven, B.J., van Vuuren, D.P., Birkmann, J., Kok, K., Levy, M., Solecki, W., 2017. The roads ahead: Narratives for shared socioeconomic pathways describing world futures in the 21st century. Global Environmental Change 42, 169-180. https://doi.org/10.1016/j.gloenvcha.2015.01.004

Pettersson, T., Öberg, M., 2020. Organized violence, 1989-2019. Journal of Peace Research 57, 597613. https://doi.org/10.1177/0022343320934986

Raleigh, C., Hegre, H., 2009. Population size, concentration, and civil war. A geographically disaggregated analysis. Political geography 28, 224-238. https://doi.org/10.1016/j.polgeo.2009.05.007

Scott, S.V., 2015. Implications of climate change for the UN Security Council: mapping the range of potential policy responses. International Affairs 91, 1317-1333. https://doi.org/10.1111/1468-2346.12455

Silva, L.L., 2017. Are basin and reservoir tillage effective techniques to reduce runoff under sprinkler irrigation in Mediterranean conditions? Agricultural Water Management 191, 50-56. https://doi.org/10.1016/j.agwat.2017.06.003

Straatsma, M., Droogers, P., Hunink, J., Berendrecht, W., Buitink, J., Buytaert, W., Karssenberg, D., Schmitz, O., Sutanudjaja, E.H., van Beek, L.P.H., 2020. Global to regional scale evaluation of adaptation measures to reduce the future water gap. Environmental Modelling \& Software 124, 104578. https://doi.org/10.1016/j.envsoft.2019.104578

Sundberg, R., Melander, E., 2013. Introducing the UCDP georeferenced event dataset. Journal of Peace Research 50, 523-532. https://doi.org/10.1177/0022343313484347

Sutanudjaja, E.H., van Beek, R., Wanders, N., Wada, Y., Bosmans, J.H.C., Drost, N., van der Ent, R.J., de Graaf, I.E.M., Hoch, J.M., de Jong, K., Karssenberg, D., López López, P., Peßenteiner, S., Schmitz, O., Straatsma, M.W., Vannametee, E., Wisser, D., Bierkens, M.F.P., 2018. PCRGLOBWB 2: a 5 arcmin global hydrological and water resources model. Geoscientific Model Development 11, 2429-2453. https://doi.org/10.5194/gmd-11-2429-2018

Tyralis, H., Papacharalampous, G., Langousis, A., 2019. A Brief Review of Random Forests for Water Scientists and Practitioners and Their Recent History in Water Resources. Water 11, 910. https://doi.org/10.3390/w11050910

van Beek, L., Hajer, M., Pelzer, P., van Vuuren, D., Cassen, C., 2020. Anticipating futures through models: the rise of Integrated Assessment Modelling in the climate science-policy interface since 1970. Global Environmental Change 65, 102191. https://doi.org/10.1016/j.gloenvcha.2020.102191

van Huijstee, J., van Bemmel, B., Bouwman, A., van Rijn, F., 2018. Modelling future urban growth with 2UP (No. PBL publication number 3255). PBL Netherlands Environmental Assessment Agency, The Hague.

van Vuuren, D.P., Kriegler, E., O'Neill, B.C., Ebi, K.L., Riahi, K., Carter, T.R., Edmonds, J., Hallegatte, S., Kram, T., Mathur, R., Winkler, H., 2014. A new scenario framework for Climate Change 
Research: scenario matrix architecture. Climatic Change 122, 373-386. https://doi.org/10.1007/s10584-013-0906-1

von Uexkull, N., 2014. Sustained drought, vulnerability and civil conflict in Sub-Saharan Africa. Political Geography 43, 16-26. https://doi.org/10.1016/j.polgeo.2014.10.003

von Uexkull, N., Buhaug, H., 2021. Security implications of climate change: A decade of scientific progress. Journal of Peace Research 58, 3-17. https://doi.org/10.1177/0022343320984210

von Uexkull, N., Croicu, M., Fjelde, H., Buhaug, H., 2016. Civil conflict sensitivity to growing-season drought. Proceedings of the National Academy of Sciences 113, 12391-12396. https://doi.org/10.1073/pnas.1607542113

Wanders, N., Wada, Y., Van Lanen, H. a. J., 2015. Global hydrological droughts in the 21st century under a changing hydrological regime. Earth System Dynamics 6, 1-15. https://doi.org/10.5194/esd-6-1-2015

Warszawski, L., Frieler, K., Huber, V., Piontek, F., Serdeczny, O., Schewe, J., 2014. The inter-sectoral impact model intercomparison project (ISI-MIP): project framework. Proceedings of the National Academy of Sciences 111, 3228-3232. https://doi.org/10.1073/pnas.1312330110

Witmer, F.D., Linke, A.M., O'Loughlin, J., Gettelman, A., Laing, A., 2017. Subnational violent conflict forecasts for sub-Saharan Africa, 2015-65, using climate-sensitive models. Journal of Peace Research 54, 175-192. https://doi.org/10.1177/0022343316682064

Wittgenstein Centre for Demography and Global Human Capital, 2018. Wittgenstein Centre Human Capital Data Explorer [WWW Document]. URL http://dataexplorer.wittgensteincentre.org/wcde-v2/ (accessed 2.12.21).

WPS Partnership, 2021. Water, Peace and Security [WWW Document]. About the Water, Peace and Security Partnership. URL https://waterpeacesecurity.org/info/about-wps (accessed 2.10.21). 


\section{Appendices}

\section{Appendix A}

In deciding which SSP-RCP combinations to use, we followed the matrix of possible combinations as provided by van Vuuren et al. (2014). Within these possibilities we included the more divergent combinations.

Table 3: Overview and descriptions of scenarios used in the study

\begin{tabular}{|l|l|l|}
\hline & Scenario description (from O'Neill et al. (2017)) & RCP \\
\hline SSP1 Sustainability & $\begin{array}{l}\text { This scenario is characterised by a gradual shift towards a } \\
\text { more sustainable and inclusive path than today's. } \\
\text { International cooperation, higher levels of health care } \\
\text { and education accelerate a downward demographic } \\
\text { trend. Challenges for mitigation and adaptation are low. }\end{array}$ & | \\
\hline SSP 2 Middle of the road & $\begin{array}{l}\text { This scenario follows the current trends in environmental } \\
\text { and socio-economic developments without fundamental } \\
\text { breakthroughs. Challenges for mitigation and adaptation } \\
\text { are moderate. }\end{array}$ & 4.5 \\
\hline SSP 3 Regional Rivalry & $\begin{array}{l}\text { This scenario is characterised by an increase in } \\
\text { nationalism, degrading environmental developments and } \\
\text { declining investments in healthcare and education, } \\
\text { leading to high population growth in lower income } \\
\text { countries. Challenges for mitigation and adaptation are } \\
\text { high. }\end{array}$ & \\
\hline
\end{tabular}




\section{Appendix B}

All indicators were conservatively resampled to a 30 arc-min spatial resolution (that is, around $10 \mathrm{~km}$ by $10 \mathrm{~km}$ ). For those indicators with discontinuous temporal coverage of the simulation period (both reference and projection period), linear interpolation was applied between available data points. The same data sources were used for both the reference period and the projection period. This list gives only the variables that are exogenously entered into the projections. Conflict in neighbouring provinces and history of conflict are based on the dependent conflict variable.

Table 4: overview of indicators used plus their data source and additional notes

\begin{tabular}{|c|c|c|c|}
\hline Indicator & Unit & Source & Notes \\
\hline Governance index & - & Andrijevic et al. (2020) & $\begin{array}{l}\text { This composite governance index } \\
\text { is computed. Variables are, inter } \\
\text { alia, GDP per capita, education, } \\
\text { and gender gap in education. A } \\
\text { more elaborated outline can be } \\
\text { found in the methods section of } \\
\text { Andrijevic et al. (2020) and its } \\
\text { supplement. }\end{array}$ \\
\hline Population count & - & van Huijstee et al. (2018) & $\begin{array}{l}\text { Future population count was } \\
\text { simulated with the } 2 \text { UP model. For } \\
\text { the reference period, this model } \\
\text { uses data from the Global Human } \\
\text { Settlement Layer (GHSL; Florczyk } \\
\text { et al. (2019)). }\end{array}$ \\
\hline $\begin{array}{l}\text { Gross domestic } \\
\text { productivity (GDP) } \\
\text { per capita } \\
\text { (Purchasing power } \\
\text { parity (PPP)) }\end{array}$ & $\begin{array}{l}\text { Billion } \\
\text { USD } \\
\text { (2005) / } \\
\text { capita }\end{array}$ & $\begin{array}{l}\text { Murakami and Yamagata } \\
\text { (2019) }\end{array}$ & $\begin{array}{l}\text { The GDP (PPP) is determined by } \\
\text { downscaling urban and non-urban } \\
\text { population at country-level and } \\
\text { city-level by using a range of } \\
\text { auxiliary variables, yielding } \\
\text { gridded values until } 2100 \text { by } 10 \\
\text { years. } \\
\text { GDP per capita (PPP) is obtained by } \\
\text { dividing the mean GDP (PPP) with } \\
\text { mean population count per water } \\
\text { province. }\end{array}$ \\
\hline Education & years & $\begin{array}{l}\text { Wittgenstein } \\
\text { Human Centre } \\
\text { Explorer (2021) }\end{array}$ & $\begin{array}{l}\text { The mean years of schooling at the } \\
\text { age of } 15-19 \text { for all sexes. }\end{array}$ \\
\hline Upper soil storage & $\mathrm{m}$ & \multirow{4}{*}{$\begin{array}{l}\text { PCR-GLOBWB } \\
\text { (Sutanudjaja et al., 2018) }\end{array}$} & \multirow{4}{*}{$\begin{array}{l}\text { All hydro-climatic variables were } \\
\text { continuously simulated with the } \\
\text { global hydrological model PCR- } \\
\text { GLOBWB at } 10 \text { arc-minutes spatial } \\
\text { resolution. Annual averages of the } \\
\text { model output formed the input for } \\
\text { this study. Anomalies were } \\
\text { determined for both reference and } \\
\text { projected period based on mean } \\
\text { reference value. }\end{array}$} \\
\hline Total evaporation & $\mathrm{m}$ & & \\
\hline Flood volume & $\mathrm{m}^{3}$ & & \\
\hline Precipitation & $M$ & & \\
\hline
\end{tabular}




\begin{tabular}{|l|l|l|l|}
\hline $\begin{array}{l}\text { Conflict in previous } \\
\text { year }\end{array}$ & - & UCDP GED v20.1/ CoPro & $\begin{array}{l}\text { For reference period, this boolean } \\
\text { indicator was determined per } \\
\text { water province by checking } \\
\text { whether there was at least 1 } \\
\text { conflict event reported in the } \\
\text { UCDP GED dataset in the previous } \\
\text { year. } \\
\text { For the projection period, conflict } \\
\text { occurrence simulated by each } \\
\text { classifier was used instead. }\end{array}$ \\
\hline $\begin{array}{l}\text { Conflict in } \\
\text { neighbouring } \\
\text { province in previous } \\
\text { year }\end{array}$ & - & UCDP GED v20.1/ CoPro \\
& & $\begin{array}{l}\text { Idem, but then the focus was not } \\
\text { on the water province, but } \\
\text { whether there was at least one } \\
\text { neighbouring water province } \\
\text { where conflict was reported } \\
\text { (reference run) or simulated } \\
\text { (projection) in the previous year. }\end{array}$ \\
\hline
\end{tabular}




\section{Appendix C}

The development over time of projected mean probability of conflict over entire Africa is depicted below. Even for these continent-average masking sub-continental differences, the 'erratic' nature of conflict onset is visible, mostly driven due to variations of the hydro-climatic variables. Clear differences in trends can be observed between a sustainable scenario (SSP1) and a scenario characterized by regional rivalry (SSP3). For the latter, results indicate that no pacification will occur until 2050, whereas the other scenarios show a clear downward trend. Additionally, continent averages show that the evolution of socio-economic development is more influential than hydroclimatological change aggregated over the whole continent which is in line with other research (Koubi, 2019; Mach et al., 2019; Witmer et al., 2017).

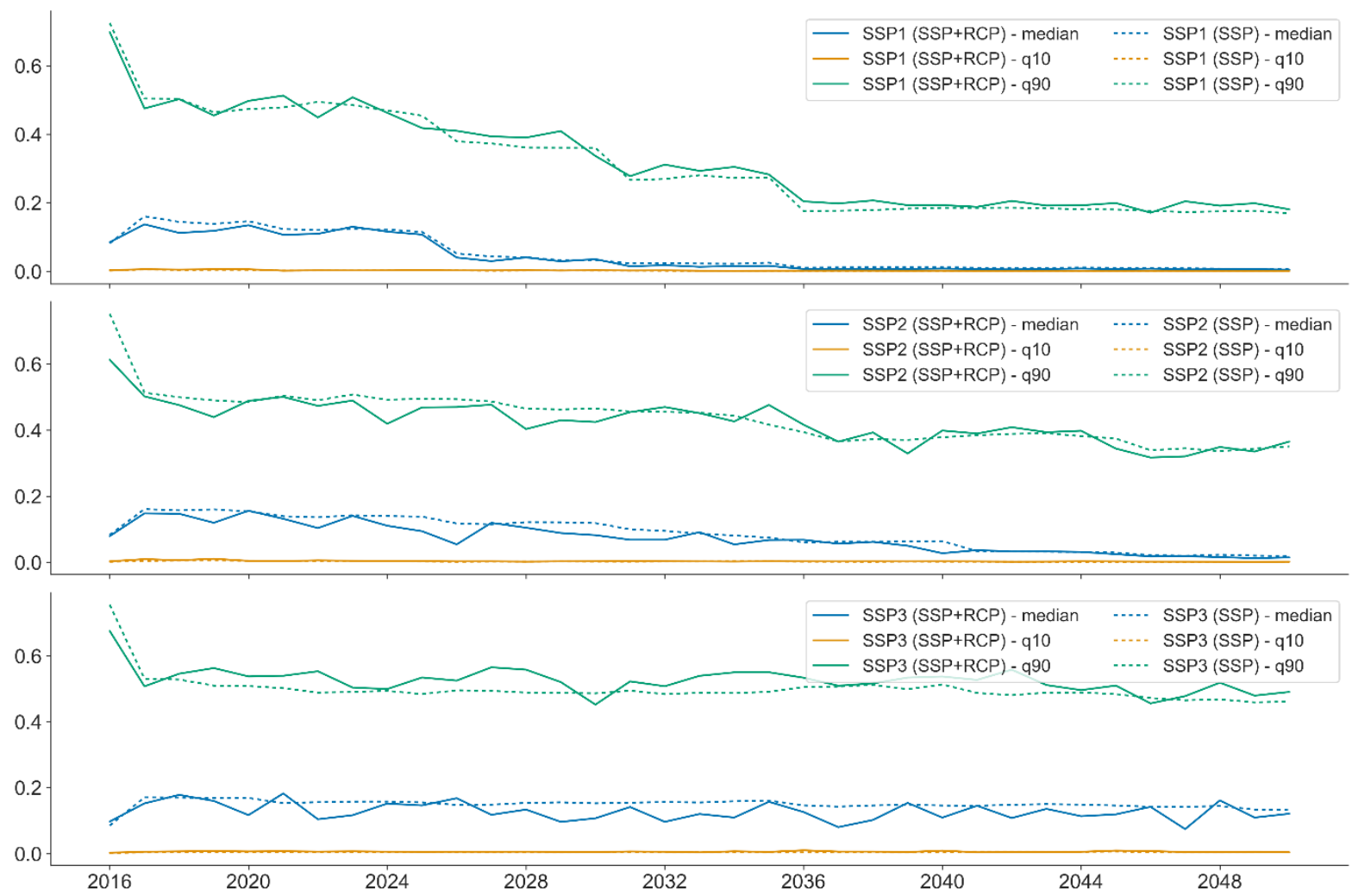

Figure 8: Continent-wide statistics of conflict probability per year for different scenarios.

We have put this information in the appendix as such timeseries need to be interpreted carefully. This is because projected conflict risk is subject to large uncertainties and since important subnational variation is masked (see Figure 6 and Figure 7). As such, one should not assume that under SSP1, the pacification process will result in a stable situation from 2036 onwards and that climate variables will have little impact everywhere across Africa. Instead, these timeseries are intended as a visualization of the resulting differences in average conflict risk between scenarios, hence informing about the spread across them. 